\title{
CHANGES IN MUSCLE COMPOSITION IN ALKALOSIS ${ }^{1}$
}

\author{
BY DANIEL C. DARROW \\ (From the Department of Pediatrics, Yale University School of Medicine, New Haven)
}

(Received for publication August 31, 1945)

Until recently alkalosis (1) seemed satisfactorily explained as a disturbance of extracellular fluids due to deficit of chloride or relative excess of sodium. In the type produced by pyloric obstruction, the increased concentration of bicarbonate in serum was readily explained by the greater loss of chloride than of sodium. Furthermore the usual quick response of these cases to the administration of sodium chloride supported this supposition. From this point of view, alkalosis was commonly regarded as involving almost exclusively the balance of sodium and chloride in extracellular fluids, and little significance was attached to incidental changes in the ionic constitution of the cytoplasm.

Studies of the tissues and electrolyte balance in cases of alkalosis have brought out evidence recently that alkalosis leads to changes in the electrolytic composition within the cells. Willson, Power and Kepler (2) and McQuarrie, Johnson and Ziegler (3) have called attention to cases of Cushing's syndrome which have persistent alkalosis and low concentration of potassium in serum. The low serum chloride and high bicarbonate of these patients is not corrected by administration of sodium chloride or ammonium chloride, but does respond to potassium chloride. These findings suggest an analogy with the effects of repeated doses of desoxycorticosterone acetate which produces replacement of large amounts of muscle potassium by equivalent amounts of sodium in experimental animals (4 to 8). Completing the analogy, the author has shown in unpublished work that rats receiving desoxycorticosterone acetate or cortical extract, while on a diet low in potassium, develop high serum $\mathrm{pH}$ and high bicarbonate as well as low chloride and potassium. The association of alkalosis with changes in the composition of intracellular fluids was also shown in a baby who lost more chloride than sodium in diarrheal stools (9). As chloride was lost more rapidly than sodium, large amounts of sodium displaced approximately

1 Aided by a grant from the Fluid Research Fund, Yale University School of Medicine, New Haven. equivalent amounts of potassium in intracellular fluids. The loss of potassium occurred either in the urine or stools. Altogether these observations suggest that alkalosis tends to be accompanied by loss of potassium from muscle cells with replacement by equivalent amounts of sodium; conversely in the cases of Cushing's syndrome, deficit of potassium with replacement by sodium in muscle cells tends to be accompanied by high bicarbonate, high $\mathrm{pH}$ and low chloride in the serum. The work presented in this paper shows that deficit of potassium with replacement by. sodium in the muscle is produced by alkalosis of the serum.

\section{METHODS}

White rats of both sexes were the experimental subjects. The methods of chemical analysis were tho previously used in this laboratory (10). Four types of experiments were carried out and the resulting cha ses in serum and muscle composition are compared to results obtained previously on normal rats.

Group 1. Under ether anaesthesia the pylorus was tied off and the rats allowed to survive until death was imminent. They were then anesthetized with nembutal and bled to death by inserting a needle into the abdominal aorta. In order to abtain blood the animals had to be killed at the end of about 24 hours. These rats could absorb no water from the gastrointestinal tract so that such adjustments as took place were carried out in the face of water deficit.

Group 2. The same procedure was carried out except that 5 per cent glucose was injected subcutaneously in 10 $\mathrm{ml}$. amounts twice a day. One rat was killed in 48 hours, 2 in 24 hours and 2 in 36 hours. Thus, while the glucose solution immobilized some extracellular electrolyte, the rats were essentially the same as group 1, except that abundant water was available.

Group 3. Twenty-five $\mathrm{ml}$. of 5 per cent solution of glucose containing $150 \mathrm{mM}$. of $\mathrm{NaHCO}_{3}$ per liter were injected into the peritoneal cavity. About four hours later, the same or slightly more fluid was removed under ether anesthesia through a small abdominal incision. Since the fluid now contained considerable amounts of chloride and about the same concentration of sodium, the procedure reduced the amount of body chloride without significant changes in body sodium. Rats subjected to this procedure lost about 10 per cent of their body weight but ate their synthetic diets well and did not act sick.

The rats in Group 3 were fed a diet made up of lactal- 
bumin, fat (Crisco), sucrose, dextrin, cod liver oil and yeast. This diet is practically free of sodium, potassium and chloride (6). Three of the rats were killed after 48 hours and 2 after 6 days.

Group 4. Four rats were treated exactly as Group 3, except that only $20 \mathrm{ml}$. of the glucose-bicarbonate solution were injected into the peritoneal cavity and the diet contained enough added $\mathrm{KH}_{2} \mathrm{PO}_{4}$ to yield $13 \mathrm{mM}$. of $\mathrm{K}$ per 100 grams of diet and enough sodium citrate to yield $30 \mathrm{mM}$. of sodium. By analysis this diet contained $1 \mathrm{mM}$. of chloride per 100 grams. These rats were killed 6 days after removing body chloride; they ate the usual amount of food 24 hours after removing the chloride. They lost about 10 per cent of their body weight.

In the rats with ligated pyloruses (Groups 1 and 2), the actual deficit of chloride could not be accurately determined because some gastric juice drooled from the mouths. Analyses of the gastric contents and urines of some of the rats in Group 2 indicated that the losses were somewhat greater than $2.5,1$ and $0.7 \mathrm{mM}$. for, respectively, chloride, sodium and potassium. Since these groups were fasting and in negative nitrogen balance, the loss of potassium is associated with the loss of nitrogen in about the same proportion as is found in muscle.

Very little urine was passed in Group 1, and from 10 to 15 per cent of the body weight was lost. In Group 2, no weight was lost and from 9 to $15 \mathrm{ml}$. of urine were passed during a period of 2 days. This volume does not differ greatly from that of the last two groups. However, Group 2 as well as Group 1 had poor renal function. In Group 2 this is evidenced by the failure to excrete water and restore sodium concentrations and by the high concentration of potassium in serum. In Group 2, the poor renal function may be in part due to immobiliaztion of water and electrolyte at the site of the injections of glucose solution. This phenomenon was observed in dogs subjected to the intraperitoneal injection of glucose and is due to a reduction in the volume of glomerular filtrate $(11,12)$. In Group 1 the poor renal function can be explained by the lack of water. In these two groups the changes in the muscle represent the equilibrium with alkalotic serum having low concentrations of chloride and high concentrations of potassium. In Group 1, serum sodium is high, while in Group 2 it is low.

In Group 3 the complete balances were determined and the average losses were 2.11, 0.8 and $2.5 \mathrm{mM}$. for chloride, sodium and potassium. Since these animals were in approximate nitrogen balance, the loss of potassium is not associated with loss of nitrogen. Balances were not determined in Group 4, but some of the urines were analyzed and contained large amounts of sodium and potassium. The loss of potassium from the muscles in this group was, therefore, not dependent on lack of available potassium.

\section{Orientation on the interpretation of muscle analyses}

Previous work has shown that muscle analyses are most readily interpreted when expressed in terms of fat-free solids (10). This arrangement is indicated because there is a close correlation between fat-free solids and nitrogen, phosphorus and potassium. The reason for this correla- tion is that the total fat-free solids are accounted for almost entirely by the fat-free solids of the intracellular fluids, and nitrogen, phosphorus and potassium are largely confined to the cells. On the other hand, the relationship between fat-free solids and muscle water, chloride and sodium is less precise. If the volume of extracellular water changes, while there is no change in the electrolyte concentrations in this fluid, the intracellular phase is unaltered. However, if the intracellular fluid has the usual composition per 100 grams of fat-free solids, the intracellular water varies indirectly with the concentration of sodium in serum (10). If there is an increase in intracellular potassium per 100 grams of fat-free solids, an increase in intracellular water can be demonstrated when extracellular concentration of sodium is normal (10). Thus the variations in total muscle water must be interpreted in terms of extracellular and intracellular water in order to have significance with reference to the cells, but the changes in potassium, phosphorus and nitrogen are apparent in the values for 100 grams of fat-free solids.

In estimating the volume of extracellular water, certain calculations may be used which give first approximations. Previous work has shown that there is a small amount of intracellular chloride as well as sodium and both are subject to variations $(7,10)$. On theoretic grounds, and from direct analyses of frog muscle, Boyle and Conway (13) pointed out that the intracellular concentration of chloride equals the extracellular concentration of potassium. This predicted value for intracellular chloride agrees with the amount of chloride which Yannet and Darrow (10) found did not react like extracellular chloride (about $1 \mathrm{mM}$. per 100 grams of fat-free solids in cat muscle).

Thus extracellular chloride is somewhat less than total muscle chloride. Within the cells, Boyle and Conway's theory predicts that there will be a rise in intracellular potassium accompanying an increase in the concentration of potassium in extracellular fluid. High concentration of potassium in serum and an increase in muscle potassium per 100 grams of fat-free solids has been found in adrenal insufficiency and after nephrectomy $(14,15)$. However, Conway and Boyle did not take into account the presence of intracellular sodium. Muscle potassium is now known to be replaced within the cells by almost equivalent amounts of sodium as a result of diets low in potassium $(4,6)$, following repeated injections of desoxycorticosterone acetate $(5,6,8)$ and in response to certain corticosteroids $(2,3)$. Administration of potassium restores the muscle potassium and decreases the intracellular sodium. Thus there is a reciprocal relationship between sodium and potassium in muscle cells. It follows that conditions which alter the relation of sodium and potassium within the cells will be modified by another condition which also changes this relationship.

In examining the data, four types of change in intracellular fluids will be encountered: (1) changes in the volume of intracellular water brought about by variations in the concentration of sodium in serum; (2) increase in intracellular potassium dependent on increase in the concentration of potassium in serum; (3) changes in 
intracellular water dependent on increase in intracellular potassium per 100 grams of fat-free solids; and (4) changes in the reciprocal relationship between muscle potassium and intracellular sodium. The last type of change is the one which is produced by alkalosis per se; but the experiments apparently show that this relation is modified by other conditions inherent in the experiments.

\section{Calculations}

In Table I, the serum analyses are presented as concentrations per liter of serum while the muscle analyses are given in amounts per 100 grams of fat-free solids. The controls and Group 2 are represented as averages with the standard deviations since the values are relatively uniform. In the other groups, the individual analyses are given in order to bring out certain significant differences within the groups.

In Table II, the derived data are given as averages. This table shows the extracellular water, the intracellular water and intracellular sodium per 100 grams of fat-free solids. The concentrations of sodium, potassium, phosphorus, nitrogen and $\mathrm{Na}+\mathrm{K}$ are also given in units per $\mathrm{kgm}$. of intracellular water. The calculations used were as follows :

$\frac{(\text { Total } \mathrm{Cl}-1)}{[\text { Extracellular } \mathrm{Cl}]}=($ Extracellular water $)$

(Extracellular water) [Extracellular $\mathrm{Na}$ ]

$=($ Extracellular $\mathrm{Na})$

$($ Total $\mathrm{Na})-($ Extracellular $\mathrm{Na})=($ Intracellular $\mathrm{Na})$

(Total water) - (Extracellular water) $=$ (Intracellular water)

In the above equations, all expressions in parentheses, ( ), refer to amounts per 100 grams of fat-free solids. Water is expressed in $\mathrm{kgm}$. and electrolyte in millimoles. The concentrations of chloride and sodium in extracellular water are represented by brackets, [ ]; they were derived from the serum concentrations of electrolyte and water, and an average Donnan factor of 0.96 . The constant, 1 , in the first equation is an average correction for chloride that does not react like extracellular chloride. In the table the intracellular concentrations were derived from the calculated volume of intracellular water when it is assumed that all nitrogen, phosphorus, potassium and calculated intracellular sodium are present in intracellular

TABLE I

\begin{tabular}{|c|c|c|c|c|c|c|c|c|c|c|c|c|c|c|}
\hline \multirow{2}{*}{ Rat } & \multirow{2}{*}{$\begin{array}{c}\text { Dura- } \\
\text { tion }\end{array}$} & \multicolumn{6}{|c|}{ Serum concentration per liter } & \multicolumn{7}{|c|}{ Muscle content per 100 grams fat-free solids } \\
\hline & & $\mathrm{H}_{2} \mathrm{O}$ & $\mathrm{Cl}$ & $\mathrm{Na}$ & $\mathbf{K}$ & $\mathrm{HCO}_{3}$ & $\mathrm{pH}$ & $\mathrm{H}_{2} \mathrm{O}$ & $\mathbf{N}$ & $\mathrm{Cl}$ & $\mathrm{Na}$ & $\mathbf{K}$ & $\mathbf{P}$ & Fat \\
\hline & hours & grams & $m M$. & $m M$. & $m M$. & $m M$. & & grams & grams & $m M$. & $m M$. & $m M$. & $m M$. & grams \\
\hline
\end{tabular}

Normal rats.

\begin{tabular}{l|r|r|r|r|r|r|r|r|r|r|r|r|r|r}
\hline Ave. & 925 & 100 & 141 & 4.0 & & & 341 & 15.6 & 7.2 & 10.0 & 49.0 & 33.4 & 0.6 \\
S.D. & 6 & 3 & 3 & 0.8 & & & 7 & 0.3 & 0.5 & 0.6 & 0.6 & 1.5 & \\
\hline
\end{tabular}

Group 1. Pyloric obstruction.

\begin{tabular}{l|l|l|l|l|l|l|l|l|l|l|l|l|l|l}
\hline 2 & 24 & 935 & 96 & 145 & 12.2 & & 7.36 & 319 & 15.6 & 3.9 & 7.6 & 51.0 & 31.2 & 18 \\
3 & 25 & 918 & 78 & 157 & 8.4 & & 7.29 & 312 & 15.6 & 3.0 & 7.3 & 49.7 & 30.9 & 17 \\
\hline
\end{tabular}

Group 2. Pyloric obstruction with hypodermoclyses of glucose solution.

\begin{tabular}{l|r|r|r|r|r|r|r|r|r|r|r|r|r|r|r}
\hline Ave. & 33 & & 52 & 129 & 8.0 & & & 347 & 15.2 & 3.0 & 7.54 & 49.0 & 31.8 & 12 \\
S.D. & & & 5 & 8 & 1.0 & & & 3.5 & 0.7 & 0.8 & 0.5 & 1.4 & 0.7 & $\begin{array}{r}12 \\
\hline\end{array}$ \\
\hline
\end{tabular}

Group 3. Chloride depletion. Diet low in $\mathrm{Cl}, \mathrm{Na}$ and $\mathrm{K}$.

\begin{tabular}{l|r|l|l|l|l|l|l|l|l|l|l|l|l|l|l}
\hline 10 & 50 & 927 & 81 & 134 & 4.9 & & 7.54 & 326 & 15.3 & 4.1 & 11.0 & 40.9 & 33.6 & 10 \\
11 & 50 & 927 & 84 & 129 & 6.4 & & 7.61 & 321 & 15.0 & 3.7 & 10.3 & 37.9 & 29.9 & 9 \\
12 & 48 & 926 & 81 & 145 & 3.6 & & & 323 & 15.0 & 3.3 & 11.0 & 41.7 & 30.9 & 10 \\
13 & 144 & 939 & 95 & 138 & 3.8 & 20 & & 320 & 14.6 & 4.2 & 11.7 & 41.8 & 31.9 & 10 \\
14 & 144 & 936 & 84 & 141 & 2.9 & 28 & & 310 & 14.8 & 3.9 & 12.6 & 40.6 & 31.4 & 13 \\
\hline
\end{tabular}

Group 4. Chloride depletion. Diet low in $\mathbf{C l}$.

\begin{tabular}{l|l|l|l|l|l|l|l|l|l|l|l|l|l|l|l}
\hline 16 & 144 & 933 & 77 & & 4.6 & 26 & & 339 & 14.7 & 5.9 & 14.6 & 41.2 & 32.0 & 10 \\
17 & 144 & 936 & 78 & 142 & 3.6 & 35 & & 330 & 14.7 & 4.2 & 15.7 & 37.6 & 30.9 & 10 \\
18 & 144 & 934 & 82 & 143 & 5.1 & 34 & & 342 & 14.7 & 5.1 & 15.9 & 35.7 & 31.0 & 11 \\
19 & 144 & 936 & 81 & 143 & 3.8 & 36 & & 335 & 14.8 & 4.6 & 14.5 & 38.3 & 32.8 & 12 \\
\hline
\end{tabular}


TABLE II

Per 100 grams fat-free solids

\begin{tabular}{|c|c|c|c|c|c|c|c|c|}
\hline \multirow{2}{*}{ Group } & \multirow{2}{*}{$\begin{array}{c}\begin{array}{l}\text { Extra- } \\
\text { cellular }\end{array} \\
\mathrm{H}_{2} \mathrm{O}\end{array}$} & \multicolumn{2}{|c|}{ Intracellular } & \multicolumn{5}{|c|}{$\begin{array}{c}\text { Intracellular concentration } \\
\text { per kgm. } \mathrm{H}_{2} \mathrm{O}\end{array}$} \\
\hline & & $\mathrm{H}_{2} \mathrm{O}$ & $\mathrm{Na}$ & $\mathrm{Na}$ & $\mathbf{K}$ & $\mathbf{P}$ & $\mathbf{N}$ & $\mathrm{Na}+\mathrm{K}$ \\
\hline $\begin{array}{c}\text { Normal } \\
1 \\
2 \\
3 \\
4\end{array}$ & $\begin{array}{c}\text { grams } \\
55 \\
25 \\
34 \\
30 \\
41\end{array}$ & $\begin{array}{c}\text { grams } \\
286 \\
291 \\
313 \\
290 \\
295\end{array}$ & $\begin{array}{c}m M . \\
1.9 \\
3.7 \\
3.0 \\
7.1 \\
9.4\end{array}$ & $\begin{array}{r}m M . \\
7 \\
13 \\
10 \\
25 \\
21\end{array}$ & $\begin{array}{l}m M . \\
171 \\
173 \\
157 \\
140 \\
127\end{array}$ & \begin{tabular}{|c|}
$m M$ \\
117 \\
107 \\
101 \\
109 \\
106
\end{tabular} & $\begin{array}{c}m M . \\
54 \\
54 \\
49 \\
51 \\
50\end{array}$ & $\begin{array}{l}m M . \\
178 \\
186 \\
167 \\
164 \\
147\end{array}$ \\
\hline
\end{tabular}

Average values for groups.

water. The concentration of $\mathrm{Na}+\mathrm{K}$ is the sum of the intracellular concentrations of sodium and potassium.

In the text and the tables the composition of muscle refers to the composition per 100 grams of fat-free solids while the concentrations are expressed per $\mathrm{kgm}$. of extracellular or intracellular water.

\section{RESULTS}

In the two rats subjected to the pyloric obstruction with diminished body water (Group 1), the concentrations of both sodium and potassium in serum are high. The slightly increased concentration of muscle potassium is explained by the high concentration of potassium in serum. The slightly low total muscle water is due to low extracellular water. This fact is brought out in Table II, where extracellular water is calculated from muscle chloride and the concentration of serum chloride. Intracellular water is a little high, though the difference is not statistically significant, and this finding is contrary to what one would expect with the high concentration of sodium in serum (10). The high total intracellular potassium explains this discrepancy (10). The increase in intracellular sodium and the decrease in muscle phosphorus in these rats are not statistically significant. In these rats, alkalosis in the presence of high concentration of potassium in serum produced few changes within the cells. The slight rise in muscle potassium is analogous to that found in adrenal insufficiency and is explained by the rise in concentration of potassium in serum (13 to 15$)$.

In Group 2, the serum concentration of sodium is low while that of potassium is high. Reflecting these changes, muscle water is high, while muscle chloride and sodium are low and muscle potassium is normal. As shown in Table II, the low concentration of muscle chloride indicates a low volume of extracellular water and a high volume of intracellular water. Intracellular sodium is not statistically increased and intracellular potassium does not show the increase in muscle potassium shown by rats with adrenal insufficiency in which a similar rise in serum potassium was found (14, 15). The increase in intracellular water is explained by the decrease in concentration of sodium in extracellular water (10). Thus reduction of the concentration of serum chloride disproportionately to that of serum sodium does not appreciably change the intracellular sodium in the presence of high concentration of potassium in serum. The lack of a rise in muscle potassium in the presence of high serum potassium may be a result of alkalosis, but the data do not prove this supposition.

In Group 3 the serum $\mathrm{pH}$ was increased in the two measurements made, but the bicarbonate is only slightly high in one of two measurements. Thus, while the method undoubtedly produced immediate alkalosis, this was partially compensated for by excretion of sodium and transfer of sodium to the cells. Serum potassium is low in rats 12,13 and 14 and normal in rat 10 and slightly high in rat 11 .

The muscles show slightly low total water, but since the muscle chloride is low, there is decrease in extracellular water and essentially normal intracellular water (Table II). In each instance muscle potassium is low per 100 grams of fatfree solids and intracellular sodium is definitely high. Thus, decrease in the concentration of serum chloride with moderate alkalosis leads to high intracellular sodium and low intracellular potassium when the concentration of serum potassium is normal or reduced.

The change in the muscle composition developed within 48 hours in rats 10,11 and 12 and since the diet was low in potassium, this deficit was not replaced in the 6 days of survival in rats 13 and 14 . These rats did not show a greater reduction in muscle potassium than the ones surviving only two days. The low concentration of serum potassium, the low muscle potassium and the high intracellular sodium may be a result of alkalosis in this group, but the experiments do not prove this because diets low in potassium produce the same type of change $(4,5,6)$. 
Group 4 showed distinctly high serum bicarbonate in three of four instances. Serum chloride is somewhat lower than in Group 3 and serum sodium essentially normal. Serum potassium is low in two of four examinations.

The muscles show normal water per 100 grams of fat-free solids, but the low muscle chloride indicates slight reduction in the extracellular water of muscle (Table II). Intracellular water is significantly though moderately increased. Muscle potassium is decreased and intracellular sodium is increased. Thus alkalosis due to loss of chloride produces reduction of intracellular potassium and increase in intracellular sodium. This change is not prevented by a diet fairly rich in potassium, and serum potassium is apt to be low under these circumstances.

In Table II it will be seen that there is only a rough correlation between the concentration of serum sodium and the concentration of $\mathrm{Na}+\mathrm{K}$ in intracellular water. The increase in the concentration of $\mathrm{Na}+\mathrm{K}$ in Group 1 and the decrease in Group 2 are accompanied by corresponding changes in the concentration of serum sodium. The fact that the increased concentration of $\mathrm{Na}$ $+\mathrm{K}$ in Group 1 is brought about by increase in muscle potassium rather than by decrease in intracellular water has already been commented on: However, in Groups 3 and 4, there is little change in concentration of serum sodium to correspond with the drop in concentration of $\mathrm{Na}+\mathrm{K}$ in intracellular water. This result is chiefly due to increase in intracellular water and not due to decrease in the amount of $\mathrm{Na}$ and $\mathrm{K}$ associated with a given amount of nitrogen. This is demonstrated by the fact that the ratios of the concentration of nitrogen to $\mathrm{Na}+\mathrm{K}$ are fairly constant. Such a finding indicates that water content relative to univalent cations is high in Groups 3 and 4 . Since these muscles have high intracellular sodium and low intracellular potassium, the findings suggest that intracellular sodium has a greater degree of dissociation than intracellular potassium, or that potassium combines with large molecules exerting relatively less osmotic pressure than the anions with which sodium is associated.

\section{REMARKS}

The data presented substantiate the hypothesis that alkalosis tends to lead to high intracellular sodium and low intracellular potassium. The state of the muscle in Groups 3 and 4 is like that described previously in animals fed a diet low in potassium $(4,5,6)$ and after repeated injections of desoxycorticosterone acetate $(5,8)$. In unpublished recent work the author has shown that normal or adrenalectomized rats receiving a diet low in potassium develop high serum bicarbonate and $\mathrm{pH}$ when they receive desoxycorticosterone acetate or cortical extract. Kepler (16) found low potassium and high intracellular sodium in the muscle of a patient with Cushing's syndrome and persistent alkalosis proven to be due to an adrenocortical tumor. He has further shown that this type of alkalosis disappears with administration of $\mathrm{KCl}$ or removal of the tumor and recurs with recurrence of the tumor. The data of Groups 1 and 2 suggest that the tendency to accumulation of intracellular sodium and loss of intracellular potassium is prevented by rise in the concentration of potassium in serum. This fact is in agreement with the observation that a diet high in potassium prevents the loss of potassium from the muscle which appears after repeated injections of desoxycorticosterone acetate (5). The distribution of muscle electrolyte in these rats fits into the author's framework for visualizing the behavior of body electrolyte (17).

Previous work $(18,19)$ from this laboratory showed that high intracellular sodium developed in rats exposed to a low atmospheric pressure for one week. These rats did not show a decrease in muscle potassium. Nevertheless, the present work makes it likely that the alkalosis developing at a low atmospheric pressure explains the high intracellular muscle sodium, and the change in muscle composition involves much the same mechanisms as the present experiments except that low atmospheric pressure was also present.

The author has observed one case of gastric tetany with alkalosis which did not respond to administration of sodium chloride for 7 days despite absence of vomiting and the administration of amounts of salt solution which made adequate sodium chloride available. Future study may show that similar cases responding slowly to sodium chloride suffer from a deficit of potassium. Since completing this study, the author has demonstrated the transfer of a large amount of sodium 
from intracellular to extracellular fluids during recovery from alkalosis following vomiting after appendectomy. Other types of refractory alkalosis must be examined from the point of view that changes within the cells make alkalosis the adjustment maintained while deficit of potassium persists.

\section{SUM MARY}

Analyses of the serum and muscle for the chief electrolytes are reported in (1) rats subjected to pyloric obstruction with water deprivation, (2) rats subjected to pyloric obstruction accompanied by subcutaneous injections of glucose and consequent abundance of water, (3) rats subjected to depletion of chloride while on a diet low in chloride, sodium and potassium and (4) rats subjected to depletion of chloride while on a diet deficient only in chloride.

In the rats with obstruction of the pylorus and deficient water, the muscle potassium per 100 grams of fat-free solids was slightly increased and there was no change in intracellular sodium. In the rats with obstruction of the pylorus and abundant water, the muscle potassium and intracellular sodium were normal. In the latter rats, intracellular water was high. The high concentration of serum potassium probably explains the high muscle potassium and lack of accumulation of intracellular sodium. The low concentration of serum sodium explains the high intracellular water in the second group.

In the alkalosis produced by depletion of chloride, serum potassium concentration is low or normal, muscle potassium is low and intracellular sodium is high. This loss of intracellular potassium occurs despite abundant potassium in the diet.

The hypothesis is proposed that alkalosis with normal concentration of serum potassium tends to cause the intracellular fluid of muscle to lose potassium and gain sodium. Evidence is brought forth from the literature for a second hypothesis, namely, that deficit of muscle potassium with replacement by sodium tends to be accompanied by serum alkalosis when renal function is normal.

The intracellular water was higher in the rats with high intracellular sodium than the concentration of serum sodium would predict. This high intracellular water could be explained by greater dissociation of intracellular sodium than intracellular potassium, or by assuming that potassium tends to be combined with large, multivalent molecules exerting relatively little osmotic pressure, while sodium combines with smaller mole. cules exerting relatively greater osmotic pressure for a given equivalent of cations.

\section{BIBLIOGRAPHY}

1. Gamble, J. L., and Ross, S. G., The factors in the dehydration following pyloric obstruction. J. Clin. Invest., 1925, 1, 403.

Gamble, J. L., Extracellular fluid and its vicissitudes. Renal defense of extracellular fluid. Control of acid-base excretion and factors of water expenditure. Bull. Johns Hopkins Hosp., 1937, 61, 151 and 174.

2. Willson, D. M., Power, M. H., and Kepler, E. J., Alkalosis and low plasma potassium in a case of Cushing's syndrome; a metabolic study. J. Clin. Invest., 1940, 19, 701.

3. McQuarrie, I., Johnson, R. M., and Ziegler, M. R., Plasma electrolyte disturbance in a patient with hypercorticoadrenal syndrome contrasted with that found in Addison's disease. Endocrinology, 1937, 21, 762.

4. Heppel, L. A., Electrolytes of muscle and liver in potassium-depleted rats. Am. J. Physiol., 1939, 127, 385.

5. Darrow, D. C., and Miller, H. C., The production of cardiac lesions by the repeated injections of desoxycorticosterone acetate. J. Clin. Invest., 1942, 21, 601.

6. Miller, H. C., and Darrow, D. C., Relation of muscle electrolyte to alterations in serum potassium and to toxic effects of injected potassium chloride. Am. J. Physiol., 1940, 130, 747.

7. Darrow, D. C., Tissue water and electrolyte. Ann. Review of Physiol., 1944, 6, 95.

8. Ferrebee, J. W., Parker, D., Carnes, W. H., Gerity, M. K., Atchley, D. W., and Loeb, R. F., Certain effects of desoxycorticosterone: Development of 'diabetes insipidus' and replacement of muscle potassium by sodium in normal dogs. Am. J. Physiol., 1941, 135, 230.

9. Darrow, D. C., Congenital alkalosis with diarrhea. J. Pediat., 1945, 26, 519.

10. Yannet, H., and Darrow, D. C., Effect of depletion of extracellular electrolytes on the chemical composition of skeletal muscle, liver and cardiac muscle. J. Biol. Chem., 1940, 134, 721.

11. Darrow, D. C., and Yannet, H., Changes in distribution of body water accompanying increase and decrease in extracellular electrolyte. J. Clin. Invest., 1935, 14, 266.

12. Harrison, H. E., and Darrow, D. C., Renal function in experimental adrenal insufficiency. Am. J. Physiol., 1939, 125, 631. 
13. Boyle, P. J., and Conway, E. J., Potassium accumulation in muscle and associated changes. J. Physiol., 1941, 100, 1.

14. Harrison, H. E., and Darrow, D. C., The distribution of body water and electrolytes in adrenal insufficiency. J. Clin. Invest., 1938, 17, 77.

15. Durlacher, S. H., and Darrów, D. C., The effect of depletion of body potassium on the time of survival after nephrectomy and ureteral ligation. Am. J. Physiol., 1942, 136, 577.
16. Kepler, E. J., Personal communication.

17. Darrow, D. C., Body-fluid physiology: The relation of tissue composition to problems of water and electrolyte balance. New England J. Med., 1945, 233, 91.

18. Darrow, D. C., and Sarason, E. L., Some effects of low atmospheric pressure in rats. J. Clin. Invest., 1944, 23, 11.

19. Darrow, D. C., Tissue electrolyte at low atmospheric pressures. Am. J. Physiol., 1944, 142, 61. 